Ensaios

Bibiograficos

Bibi iogl

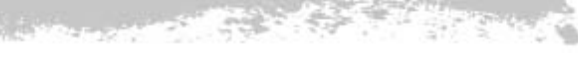

\section{Bernardino-Costa, Joaze (org). Hoasca, ciência, sociedade e meio ambiente. Campinas, Mercado de Letras, 20II. 360 pp.'}

Rosa Melo Com a publicação do livro Hoasca, Ciência, Sociedade e Meio Ambiente - lançado em

(UnB) 2011 pela editora Mercado de Letras - o Centro Espírita Beneficente União do Vegetal

Beatriz Caiuby Labate (UDV) floresce e dá sinais de vitalidade ao mostrar-se assertivo, bem organizado e de

(CIDE) caráter confessional. O volume contou com a organização de Joaze Bernardino-Costa, sociólogo da Universidade de Brasília, que desenvolve pesquisas sobre desigualdade racial e também pertence ao Quadro de Mestres da sociedade religiosa. A instituição é conhecida no meio ayahuasqueiro por sua institucionalização. A UDV possui 13.839 sócios em 104 núcleos (dois nos Estados Unidos e um na Espanha), 39 pré-núcleos e 12 distribuições autorizadas (três nos Estados Unidos, um em Lisboa e um em Londres) (Bernardino-Costa 2011:36). Apesar de ter sido fundada apenas em 1961 e ser numericamente pouco significante, seu percurso no campo religioso evoca importantes questões sociológicas, o que torna o lançamento do livro um marco no âmbito dos estudos desta temática.

O livro é derivado do esforço da UDV em divulgar seu II Congresso Internacional da Hoasca, realizado em 2008, em Brasília. O evento, que reuniu mais de mil participantes, contou com palestras de adeptos e convidados de honra, entre eles alguns pesquisadores. A obra é composta por três partes, destinadas aos temas ciência, sociedade e meio ambiente, que reúnem quarenta e quatro autores em textos de Apresentação, Introdução, Abertura, além de trinta artigos.

O II Congresso Internacional e o livro organizado por Bernardino-Costa devem ser entendidos dentro da trajetória histórica da UDV de busca de reconhecimento e legitimação pública, que envolve a realização de diversas publicações e congressos (internos e externos). $\mathrm{O}$ evento anterior de maior peso foi I Congresso Internacional da Hoasca, que ocorreu em 1995, no Rio de Janeiro. A primeira obra produzida pelo grupo intitula-se União do Vegetal - Hoasca: Fundamentos e Objetivos, e foi publicada em 1989. Trata-se de um pequeno livro de fabricação doméstica composto por uma introdução, pela compilação dos eventos jurídicos e documentos históricos que 
marcaram a história da sociedade religiosa. No texto, a UDV se autoidentificava como uma "seita" que objetivava se distinguir no interior do campo das religiões urbanas da ayahuasca, como pouco conhecida pela sociedade nacional e estigmatizada pela associação com o uso de drogas.

A publicação de 1989 e o livro aqui analisado são pontuados pela suspensão do uso da ayahuasca em 1985, bem como pela reiteração de que o "chá é comprovadamente inofensivo à saúde". A entrada da bebida na lista de substâncias proscritas pelo governo, entre 1985 e 1986, marca o início da acentuação do processo de institucionalização. $O$ contraste entre as duas publicações denota aspectos históricos importantes do crescimento da UDV, bem como alianças simbólicas e práticas incorporadas ao seu reconhecimento jurídico como religião. O último congresso e livro revelam uma atitude mais proativa do grupo em buscar visibilidade pública e reconhecimento acadêmico, diferente da discrição anterior no trato institucional com a sociedade envolvente.

O lançamento do livro Hoasca: Ciência, Sociedade e Meio Ambiente faz parte do contexto de comemoração dos 50 anos da UDV, ocorrido em julho de 2011. Sob esta chancela, a instituição promoveu uma série de atos - publicações, festividades internas e celebrações públicas. Ao lado da publicação em tela, outros lançamentos constroem o percurso da UDV, como: Relicário: Imagens do Sertão, do jornalista Edson Lodi (2010), que, através de cantigas e acordes sertanejos, imprime tons e cores da vivência na União do Vegetal; e a compilação Parlamento Reverencia os 50 anos da União do Vegetal, organizada por Wolney Queiroz, deputado federal do Partido Democrático Trabalhista (PDT) de Pernambuco e pertencente ao Corpo do Conselho do grupo. Em parceria com a Deputada Perpétua Almeida, do Partido Comunista do Brasil (PCdoB) do Acre, Queiroz foi um dos solicitantes da sessão solene de homenagem à UDV, realizada na Câmara dos Deputados em Brasília, em 11 de julho de 2011. Os discursos realizados na ocasião, bem como artigos de líderes e o mapa de oitenta e três homenagens realizadas em Assembleias Legislativas e Câmaras Municipais, compõem seu livro. Outro destaque dos eventos do cinquentenário é a biografia do fundador - Mestre Gabriel, O Mensageiro de Deus - escrita por Ruy Fabiano (2012), mestre da UDV e jornalista conhecido por suas posições polêmicas.

O livro de Bernardino-Costa guarda algumas semelhanças com relação aos demais, porém, nos interessa debater aqui determinadas especificidades desta obra. Elas revelam importantes aspectos do atual contexto político e histórico da UDV, sobretudo no que diz respeito ao diálogo com a pesquisa científica e acadêmica. Passemos a obra: dos cinco textos de abertura, quatro são assinados por lideranças internas. Estes artigos apresentam a divisão administrativa da UDV em departamentos, conselhos e coordenações que estruturam o poder e a hierarquia interna; além de apresentarem a história da UDV, sua expansão e conquistas, empreendidas desde os "primórdios"; o decoro e o equilíbrio que alicerçam suas intenções e práticas; a pertença ao código cristão da caridade. $\mathrm{O}$ quinto texto é da deputada Perpétua Almeida, que, não sendo membro, presta homenagem e apoio ao pedido de patrimonialização da ayahuasca. Este pedido salienta uma novidade histórica ao campo: a aliança de três matrizes religiosas da ayahuasca no pleito intitulado "patrimonialização de um direito sagrado" (:56). 
A Parte I - Hoasca e Ciência - é composta por nove artigos e subdividida em três temáticas: dois textos apresentam aspectos constitutivos do Departamento Médico Científico e da Comissão Científica, órgãos institucionais envolvidos com a promoção de pesquisas internas e projetos de pesquisa externos que visem estudar a UDV; um artigo traz o depoimento pessoal de um farmacólogo que participou do I Congresso Internacional da Hoasca; seis artigos reportam achados depurados do projeto "Hoasca na Adolescência" - financiado majoritariamente pelo Heffter Institute, levado a cabo por pesquisadores da University of California/Los Angeles e da Universidade Federal de São Paulo, com vistas a avaliar o impacto do uso do "chá" no desenvolvimento dos jovens da UDV. O livro oferece tradução para o português de quatro artigos publicados originalmente em inglês no Journal of Psychoactive Drugs, em 2005. A ênfase é apresentar os jovens "caianinhos" (discípulos da UDV) a partir de forte aderência aos valores coletivos e destacar sua saúde mental, isto é, demonstrar que não apresentam diferenças relevantes nos campos neurológicos e psiquiátricos em relação ao grupo controle. A novidade é a inclusão de dois novos artigos sobre essa pesquisa, escritos por Otávio Pereira e Luiza Alonso: enquanto o primeiro narra os intricados e desafiantes aspectos logísticos envolvidos na realização do estudo, o segundo propõe uma discussão metodológica sobre os aspectos qualitativos da pesquisa.

A Parte II - Hoasca e Sociedade - compõe-se de doze artigos em torno dos temas UDV no Brasil, no Exterior e Instituições Hoasqueiras Históricas (denominação que a UDV atribui às religiões selecionadas para participarem do II Congresso Internacional). Na primeira subdivisão se lê sobre os objetivos institucionais da União; sobre os eventos que envolveram a UDV e os órgãos governamentais de controle de drogas; sobre as ações de beneficência promovidas pelo grupo; as narrativas de líderes religiosos do Alto Santo e da Barquinha (matrizes ayahuasqueiras não expansionistas); as experiências jurídicas nos EUA e Espanha - com destaque para a vitória da UDV na Suprema Corte Norte Americana. Trata-se de um bom resumo e de um panorama histórico dos eventos ocorridos em diversos países. Tem o mérito de tornar acessível em português dois artigos publicados anteriormente pela instituição no livro The internationalization of ayahuasca (Labate \& Jungarbale 2011). A principal novidade dessa parte é o escrito de John Boyd, advogado da UDV nos Estados Unidos, que traz um emocionante depoimento pessoal sobre sua experiência profissional no heroico processo de enfrentamento da UDV com o governo norte-americano. Essa discussão está embasada, sobretudo, na ideia de "liberdade religiosa" operante no circuito público, democrático e moderno.

A parte III - Hoasca e Meio Ambiente - é formada por nove artigos que revelam o empenho e os resultados positivos da UDV no campo de pesquisas etnobotânicas, na conservação ambiental do cipó e do arbusto que compõem a ayahuasca - o "mariri" (Banisteriopsiscaapi) e a "chacrona" (Psychotriaviridis). Os textos apresentam diferentes projetos desenvolvidos, tais como o estudo do comportamento e taxonomia das espécies; a criação de um banco de germoplasma; a recuperação de áreas degradadas para implantação de sistema agroflorestal e manejo sustentável das duas espécies.

O leitor é conduzido por um fascinante caminho de iniciativas que combinam conhecimento científico com acumulado saber empírico, o que leva a UDV à sua autossuficiência no consumo das espécies unidas na hoasca. 
O artigo de Maria Alice Corrêa traz a identificação inédita das variedades de "chacrona" - conhecidas até então apenas pelos seus nomes vernaculares no âmbito do grupo ("cabocla", "caianinha" e "caneluda") - com espécies botânicas descritas na literatura (Psychotriaviridis, $P$. leiocarpa e $P$. carthagensis, respectivamente). A seção conclui expondo o histórico e as ações ambientalistas da Organização Não Governamental Associação Novo Encanto, um "braço ecológico" pouco conhecido da UDV, que possui diferentes projetos espalhados pelo Brasil. Esta parte do livro é, no nosso entender, a maior contribuição e inovação da obra, pois é relativa à notória característica da UDV de busca de uma grande expansão (que implica em extensa produção de ayahuasca) acompanhada de sustentabilidade, eficiência e organização - o que a diferencia mundialmente dos demais grupos ayahuasqueiros.

O resultado é um livro que constitui grande fonte de pesquisa, permite múltiplas leituras e apropriações. Sua leitura instiga leigos a conhecerem a diversidade e desenvolvimento da UDV em particular, e a riqueza deste fenômeno cultural como um todo. Deve também estimular pesquisadores de diversas disciplinas a se interessarem pelo assunto e colaborarem na consolidação do emergente campo de estudos sobre a ayahuasca. Em suma, o livro Hoasca: Ciência, Sociedade e Meio-Ambiente é referência imediata para qualquer pessoa interessada no assunto.

O livro se apresenta sob autoria de atores sociais situados em uma fronteira entre "religião e academia, religião e Estado e religião e sociedade nacional" (:12). Além do propósito de apresentar a UDV à sociedade e aos poderes instituídos, o grupo questiona a primazia do discurso acadêmico sobre o que é a União e reivindica o direito "às próprias visões de si mesmo" (como afirma Otávio Velho, na 'orelha' da obra). Na Apresentação - assinada pelo organizador da obra e organizador do II Congresso, José Roberto Campos de Souza - rejeita-se explicitamente a classificação do livro como uma "contribuição nativa ao campo de estudos" (:12). A UDV pretende, com a publicação, promover um "diálogo com a literatura acadêmica e científica pertinente" (idem), apresentando-se, portanto, como uma forma religiosa que busca expressão pública através de uma demanda por reconhecimento acadêmico, "instaurando um diálogo mais simétrico com a academia” (:19).

Tais objetivos são, em nosso entender, legítimos e estão em consonância com o espírito da antropologia contemporânea. Com o intuito de levar a sério a proposta de diálogo e simetria com a academia, e como coparticipantes da construção deste campo de conhecimento, teceremos algumas considerações críticas no sentido de aprimorar a discussão, sem a pretensão de esgotarmos o assunto ou desmerecermos as inúmeras contribuições da obra.

O discurso de apresentação da instituição religiosa, situada enquanto objeto e autora de uma análise científica, assume a pertença religiosa dos autores, mas não realiza o esforço de submetê-la à objetivação reflexiva - metodologia que, como nos alerta Bourdieu (1998), é capaz de conter o risco de se tomar a crença como modelo de análise. Neste sentido, cabe a pergunta: a quem se destina o livro? Diferentemente do postulado pelos organizadores, parece destinar-se, sobretudo, aos próprios adeptos. Para pesquisadores acadêmicos, por sua vez, parece funcionar como uma fonte de dados sobre o "pensamento nativo". Embora a obra seja de uma sofisticação e capacidade de articulação com o conhecimento acadêmico superior a do livro anterior, ou aos demais lançamentos contemporâneos (que, aliás, não têm esta motivação), a sensação é que, novamente, estamos diante 
de um livro "institucional". Para reforçar nossa análise, procuraremos aqui refletir em que medida o livro dialoga com a literatura acadêmica existente sobre o assunto e é rigoroso em relação aos fatos históricos que marcaram o desenvolvimento das religiões ayahuasqueiras no Brasil.

Nos textos onde lemos sobre a Comissão Científica e as relações institucionais são dadas algumas pistas para a compreensão dos limites teóricos e analíticos aos quais nos referimos. A Comissão Científica, formada por membros situados no topo da hierarquia da UDV, é imbuída da "análise, aprovação e acompanhamento" (:71) de variados projetos de pesquisa acadêmica. A ideia de "acompanhamento" de pesquisas justifica-se por "... garantir que a produção científica seja compatível com os objetivos da nossa Instituição" (idem). Embora estes interesses de preservação da privacidade religiosa e representação pública da instituição devam ser considerados, é evidente o impacto de tal postura no necessário processo de diferenciação das esferas religiosa e científica no campo do conhecimento. Estes temas foram discutidos, aliás, em notas metodológicas em trabalhos anteriores de nossa própria autoria. No livro, há a repetição contínua de que a UDV respeita a realização de pesquisas e a autonomia dos pesquisadores, que fica evidente nas seguintes citações: "a União do Vegetal participou tão somente da logística daquela pesquisa, não interferindo na definição da metodologia nem na interpretação dos dados" (:14); "pesquisadores independentes" (:85); "não interferência" (:95); "aceitação da ciência acadêmica" (:197)"; "Da mesma maneira que na área das ciências biológicas, esse diálogo [com cientistas sociais, principalmente da área da antropologia] sempre foi bem vindo na instituição (:66)." O livro se furta, contudo, a promover uma reflexão crítica sobre a relação da UDV com o conhecimento científico produzido sobre ela - seja por parte dos membros da Comissão Científica ou dos pesquisadores acadêmicos convidados a escrever na obra. Perde-se a oportunidade de aprofundar o "dialogo simétrico" e, ao mesmo tempo, elimina-se a dissonância presente no delicado cenário que costuma marcar as relações entre pesquisadores e seus sujeitos de pesquisa. Conhecemos o campo e temos notícias de várias tensões envolvendo a UDV e estudiosos da área de ciências humanas no decorrer do desenvolvimento de suas pesquisas.

Diferentemente do distanciamento acadêmico, uma postura udevista religiosamente orientada transparece em todo o livro. Provavelmente o melhor exemplo disto é a repetição exaustiva de que o chá é "comprovadamente inofensivo à saúde" ou de que os "estudos científicos comprovaram o que o Mestre Gabriel disse: a hoasca é inofensiva à saúde" (páginas 43, 48, 69, 155,153 161, 241, entre outras; os livros de Queiroz e Fabiano também insistem repetidamente neste ponto). Os autores destas afirmações se referem, sobretudo, ao projeto "Farmacologia Humana da Hoasca" e à pesquisa "Hoasca na Adolescência". Conforme assinalam alguns estudiosos (Labate, Rose \& Santos 2008), a pesquisa sobre a Hoasca foi um projeto piloto, realizado com apenas quinze sujeitos, todos homens e com longa experiência de consumo da ayahuasca, o que implica uma importante limitação na coleta dos dados e na possibilidade de generalização, uma vez que pessoas que experienciaram efeitos adversos tenderiam a sair do grupo e não a permanecer nele. A pesquisa com os adolescentes corrigiu alguns desses problemas ao aumentar a amostra (40 pessoas), incluir maior diversidade de gênero e de tempo de participação dos sujeitos no grupo. Contudo, há ainda limitações, como o tamanho da amostra. Embora estas duas pesquisas sejam valorosas e 
tenham caráter inaugural e pioneiro, o cenário científico de pesquisas biomédicas atuais não permite uma afirmação tão genérica e peremptória como a de que o uso da ayahuasca seja "inofensivo à saúde".

A avaliação dos efeitos de uma substância psicoativa, especialmente em setting natural, é de enorme complexidade, e implica em desafios metodológicos e legais. O campo de estudos biomédicos sobre o uso (ritual) da ayahuasca está apenas desabrochando; é importante a realização de mais estudos longitudinais (acompanhamento durante alguns anos), prospectivos (avaliação antes da experiência) ou que levem em conta dados retroativos, com metodologias que permitam estabelecer relações causais e avaliar a persistência das mudanças comportamentais. Por outro lado, as pesquisas existentes não podem ser tomadas como evidência absoluta dos "efeitos da ayahuasca", pois permanece o desafio de estabelecer os limites entre os aspectos que seriam resultado de "adesão religiosa" ou "efeitos da substância psicoativa". Por fim, é necessário contemplar as limitações políticas e contextuais mais amplas envolvidas na produção deste tipo de conhecimento, como o "viés no recrutamento" dos sujeitos de pesquisa e o fato de esses estarem, frequentemente, considerando-se o estigma da ayahuasca, ansiosos por "pontuar bem" nas entrevistas e formulários. O texto de Luiza Alonso, por exemplo, aborda lateralmente a clássica incidência da cultura religiosa na esfera privada, apontando a resistência dos jovens da UDV em se posicionarem individualmente sobre os temas elencados durante a pesquisa, sabidos tabus em suas famílias: afiliação religiosa, drogas e sexo.

A bibliografia científica sobre alucinógenos em geral e ayahuasca em particular indica a necessidade de cautela no consumo dessas substâncias em determinados contextos e tipos de populações, tais como portadores de problemas mentais ou pessoas que estejam utilizando certos medicamentos psiquiátricos. Note-se que dois pesquisadores membros da UDV, Francisco Assis de Sousa Lima e Luís Fernando Tófoli, na obra citada acima, The Internationalization of Ayahuasca (In Labate \& Jungarbale 2011), produziram um artigo que apresenta uma visão mais mediada dos eventuais riscos da ayahuasca, reportando algumas ocorrências de eventos psicóticos nos quadros da UDV. Essa discussão não foi incluída no II Congresso Internacional e o livro de Bernardino-Costa não cita esse artigo, nem apresenta uma reflexão mais nuançada e crítica sobre os eventuais riscos associados ao uso da ayahuasca, ou as implicações e limitações das pesquisas biomédicas a respeito. Estas nossas pontuações não pretendem, é claro, negar um interesse genuíno da UDV pela discussão científica ou as evidências científicas dos potenciais terapêuticos da ayahuasca e da sua razoável segurança de uso em determinados contextos.

A superestimação, pelos autores do livro, das implicações biomédicas e científicas das duas pesquisas desenvolvidas no âmbito da UDV está ligada à superestimação do seu papel legal. Historicamente, a regulamentação do uso da ayahuasca no Brasil não tem relação com as pesquisas desenvolvidas no âmbito da UDV, como frequentemente parecem pensar e mesmo afirmar alguns adeptos do grupo. Em primeiro lugar, o projeto "Farmacologia Humana da Hoasca" foi publicado no início dos anos 90, enquanto a exclusão do cipó Banisteriopsiscaapi da antiga lista da DIMED (Divisão de Medicamentos do Ministério da Saúde) ocorreu em meados dos anos 80. O livro parece, implicitamente, sugerir que a pesquisa "Hoasca na Adolescência" influenciou decisões legais sobre o consumo da ayahuasca por crianças e jovens no país (:158 e 176). A pesquisa dos adolescentes foi, contudo, publicada em junho de 2005, enquanto a primeira referência à permissão do consumo da ayahuasca por 
mulheres grávidas e crianças aparece pela primeira vez no “Parecer da Câmara de Assessoramento Técnico-Científico (CATC) sobre o uso religioso da Ayahuasca", de 2004. Tal referência consolida-se na Resolução n. 5 do CONAD (Conselho Nacional de Políticas Sobre Drogas), também de 2004. Ambos os documentos, assim como outros que os seguiram, não citam essas pesquisas como fontes de suas decisões, antes enfatizam questões antropológicas e culturais na defesa da liberdade religiosa. Em suma, a regulamentação do consumo da ayahuasca no Brasil por adultos, assim como por jovens, crianças e mulheres grávidas não se deu porque a ayahuasca não é considerada uma "droga" ou porque estudos científicos comprovaram que a ela "é inofensiva à saúde".

A tendência a supervalorizar o papel da UDV na regulamentação do uso da ayahuasca é, por sua vez, complementada pela ausência de referências ao papel de outra vertente ayahuasqueira, o CEFLURIS (Centro Eclético da Fluente Luz Universal Raimundo Irineu Serra), atual ICEFLU (Igreja do Culto Eclético da Fluente Luz Universal Patrono Sebastião Mota de Melo), no processo. Este grupo esteve presente, junto com a UDV, em debates com representantes do governo e pesquisadores acadêmicos para regulamentar estas práticas durante vinte e cinco anos, e também foi personagem central na expansão do uso da ayahuasca para além da Amazônia. Não obstante, ele aparece citado apenas lateralmente em um dos artigos. Nenhum representante do CEFLURIS/ ICEFLU foi convidado a participar do II Congresso Internacional e da Mesa que geraram a seção do livro intitulada "Instituições Hoasqueiras Históricas". Nessa classificação, a seleção do que é "histórico" ou "tradicional" no campo da ayahuasca se deu a partir de um critério de alianças políticas e não histórico ou sociológico.

Analogamente, o livro representa a UDV como mantenedora de contato próximo e tolerante com as demais vertentes ayahuasqueiras, e destaca o "contato amistoso e boas relações do mestre Gabriel com outros líderes hoasqueiros" (p. 16). Excluem-se as reflexões acadêmicas sobre a trajetória histórica de relações e trocas entre os grupos, e as rivalidades presentes no campo ayahuasqueiro. Não aparece nenhuma referência crítica aos debates em torno da História da Hoasca e do episódio dos Mestres de Curiosidade - aspectos presentes em diversos autores, tais como Beatriz Labate (2004), Sandra Goulart (2004), Afrânio Patrocínio de Andrade (2004), Rosa Melo (2010, 2011), Luis Eduardo Luna (1995) e Anthony Henman (1986).

Outros recursos de autolegitimação recorrentes, comuns no campo religioso, incluem menções às atividades de beneficência e à conquista do título de "instituição de utilidade pública". Nesse sentido, são interessantes as semelhanças entre os discursos de comemoração do cinquentenário da UDV em sessão solene no plenário da Câmara Federal e os discursos de comemoração do centenário da Igreja Assembleia de Deus, ocorrido no mesmo local e em data próxima (em 14 de junho e 11 de julho de 2011, as comemorações da AD e da UDV, respectivamente). As duas religiões anunciam proveniência da floresta, recordam os primeiros tempos de estigma e perseguição, celebram a expansão e revelam interesse em se expressar publicamente articulando-se à esfera do Estado, em associação com o poder constituído. No caso da UDV, tal discurso de autolegitimação está em consonância com seus princípios de "respeito às leis do país" e de "cativar as autoridades" - aspectos fundamentais do ethos udevista, transformados em mote do livro de Queiroz, anteriormente citado. 
A imagem da UDV promovida pelo livro aqui analisado sustenta-se em outro conjunto de reivindicações, de que essa sociedade religiosa possuiria "traços igualitários", "caráter participativo" e "democrático" por promover eleições para seus quadros administrativos (:27-36). Omite-se que na UDV as mulheres não chegam ao grau hierárquico máximo, que é o cargo de Mestre e consequentemente, embora participem localmente em seus núcleos, não participam das eleições mais amplas e raramente alcançam cargos significativos de liderança administrativa. Isto gera protestos e incômodos internos. Desempregados, pessoas divorciadas, não casadas e homossexuais costumam ascender na hierarquia interna com maior dificuldade e não chegam ao grau de Mestre - o que impõe alguma seletividade à ideia de "igualdade".

Através da ênfase no trabalho e na família, a UDV aposta nos seus aspectos cristianizados no sentido da ascese moral. Sua aproximação com tradições não cristãs, conforme notaram Goulart (2004) e Melo (2011), tende a ser diminuída. Por exemplo, na seção 'Hoasca e Meio Ambiente", Maria Alice Corrêa observa a existência de dez "plantas companheiras", encontradas próximas ao habitat natural da "chacrona" e do "mariri", as quais indicariam a presença de "reinados" destas espécies. Tais plantas, argumenta a autora, poderiam contribuir na "comunicação bioquímica" incidente na composição da hoasca, explicitando um intricado sistema de comunicação entre plantas, e entre plantas e homens. Das dez "plantas companheiras" abordadas por Corrêa (sororoca, palmeiral, samaúma, apuí, castanheira, pau d'arco, mulateiro, maçaranduba, carapanaúba, breuzin - :286), oito delas (samaúma, apuí, castanheira, pau d'arco, mulateiro, maçaranduba, carapanaúba, breuzin) coincidem com as espécies utilizadas em uma interessante prática vernacular udevista conhecida como "Nove Vegetal" ou "Nove Vegetais". Trata-se de uma prática, assimilada das tradições indígena e mestiças da Amazônia, de acrescentar outras espécies vegetais na cocção do cipó e da folha. O uso dos Nove Vegetais foi eliminado pela UDV no passado devido ao receio de ser associada ao estigma do charlatanismo e uso indevido do vegetal como forma de terapia. A ausência de referência por parte de Corrêa à existência dos "Nove Vegetais" provavelmente segue a mesma lógica de preocupações legais e biomédicas que levou à extinção desta tradição pelo próprio grupo.

Permitir o debate laicizado do sacramento, para além do embate estritamente jurídico, é um dilema para uma religiosidade como a udevista, que transita entre o cristianismo e a magia - o aspecto mágico, a propósito, é muito mais candente no livro de Fabiano (2012), onde Mestre Gabriel é descrito como uma espécie de curador popular e profeta portador de dons especiais. A tensão entre o espiritismo kardecista-cristão e o espiritismo afro e o curandeirismo amazônico popular é, contudo, uma questão imprescindível - não aos estudos farmacológicos ou do meio ambiente, mas àqueles registrados sob a rubrica do social e do cultural. Na publicação de 1989 (União do Vegetal - Hoasca: Fundamentos e Objetivos), o sentido instituído da "burracheira" - nome dado ao estado ou efeitos do consumo da hoasca - preenche diversas páginas em correlação com outros estados alterados de consciência tradicionais. O tema da "burracheira" também esteve presente nos congressos anteriores (1991, 1993, 1995). Ele aparecia sob um registro duplo: o da capacidade de cura e uma orientação discursiva que a oblitera. No II Congresso Internacional de 2008 e no livro de Bernardino-Costa (2011) diminuíram painéis que uniam (ex) seringueiros, os "caboclos" da UDV, e profissionais da biomedicina, "os doutores". 
Se apontamos aqui algumas limitações da abordagem acadêmica promovida pelo livro, é justamente esta tensão e hibridismo entre ciência e religião que tornam a UDV um fenômeno tão atraente - e livro analisado valioso. Através do desejo de reconhecimento público e de sua abertura para pesquisa, ou melhor, sua visão de que pode haver uma convergência entre conhecimentos espirituais (a "ciência de Salomão") e científicos (a "ciência acadêmica"), a UDV adiciona criativa e constantemente novos elementos ao seu repertório religioso e cultural. Neste sentido, as ideias expressas no livro tendem a ser incorporadas ao imaginário do próprio grupo, fortalecendo-o. Por fim, se o objetivo da obra era elevar a UDV a outro patamar na sua representação pública e provocar acadêmicos, certamente ela foi duplamente bem sucedida.

Rosa Virginia Araújo de Albuquerque Melo tem Doutorado em Antropologia Social pela Universidade de Brasília, em cujo Departamento de Antropologia é atualmente professora substituta.

Beatriz Caiuby Labate é Doutora em Antropologia Social pela Universidade Estadual de Campinas e atualmente pesquisadora no Centro de Investigación y Docencia Económicas no México. 


\section{NOTAS}

1 Este texto é uma versão levemente alterada do original "The UDV Religion, Science and Academic Research". Anthropology of Counsciousness. 2013 (no prelo). 
BERNARDINO-COSTA, Joaze (org). 2011. Hoasca, ciência, sociedade e meio ambiente. Campinas: Mercado de Letras. BOURDIEU, Pierre. 1998. Introdução a uma sociologia reflexiva. In O Poder Simbólico. Rio de Janeiro: Bertrand Russel.

FABIANO, Rui. 2012. Mestre Gabriel, O Mensageiro de Deus. Brasília: Pedra Nova.

GOULART, Sandra. 2004. Contrastes e continuidades em uma tradição amazônica: as religiões da ayahuasca. Tese de Doutorado. Campinas, SP: Programa de Pós-Graduação em Filosofia e Ciências Humanas, Unicamp.

HENMAN, Anthony. 1986. “Uso del ayahuasca en un contexto autoritario. El caso de la União do Vegetal en Brasil”. América Indígena XLVI (1): 219-234.

LABATE, Beatriz; ROSE, Isabel \& SANTOS, Rafael. 2008. Religióes Ayahuasqueiras: Um Balanço Bibliográfico. Campinas, SP: Mercado de Letras.

LABATE, Beatriz \& JUNGARBALE, Henrik (orgs). 2011. The internationalization of ayahuasca. Berlin: Lit Verlag.

LIMA, Francisco Assis de \& TÓFOLI, Luis Fernando. 2011. “An Epidemiological Surveillance System bythe UDV: Mental Health Recommendations Concerning the Religious Use of Hoasca" In Beatriz Labate \& Henrik Jungarbale (orgs). The internationalization of ayahuasca. Berlin: Lit Verlag.

LODI, Edson. 2010. Relicário: Imagens do Sertão. Brasília: Pedra Nova.

LUNA, Luís E. 1995. Ayahuasca em cultos urbanos brasileiros. Estudos contrastivos de alguns aspectos do Centro Espírita e obra de Caridade Príncipe Espadarte Reino da Paz (a Barquinha) e Centro Espírita Beneficente União do Vegetal (UDV). Trabalho apresentado para o concurso de professor adjunto em Antropologia de Ciências Sociais da UFSC. Florianópolis: Departamento de Antropologia, UFSC.

MELO, Rosa V. 2010. “Beber na Fonte”: adesão e transformação na União do Vegetal. Tese de Doutorado. Brasília: Programa de Pós-Graduação em Antropologia Social, UnB.

2011. "A União do Vegetal e o transe mediúnico no Brasil". Religião e Sociedade 31(2): 130-152.

Parecer da Câmara de Assessoramento Técnico-Científico Sobre o uso Religioso da Ayahuasca, 17 de agosto, Brasília, 2004.

PATROCÍNIO de Andrade, A. 2004. "Contribuições e Limites da União do Vegetal para a Nova Consciência Religiosa" In Beatriz Labate \& Wladimir Araújo (orgs). O Uso Ritual da Ayahuasca. Campinas: Mercado de Letras.

QUEIROZ, Wolney (org.). 2011. Parlamento Reverencia os 50 anos da União do Vegetal. Câmara dos Deputados. Disponível em: http://blog.udv.org.br/wp-content/uploads/2012/02/UDV-50-ANOS-LIVRO-Parlamento-reverenciaos-50-anos-da-UDV1.pdf

Resolução n. 05 [Resolution no. 05]. Brasília: CONAD, Nov., 4. 2004,

UNIÃO DO VEGETAL.1989. Hoasca: Fundamentos e Objetivos. Centro de Memória e Documentação Sede GeralBrasília, DF, 1989. 